\title{
Climate change: comparative impact on developing and developed countries
}

\author{
PAUL CHINOWSKY ${ }^{1 *}$, CAROLYN HAYLES ${ }^{2}$, AMY SCHWEIKERT $^{3}$, \\ NIKO STRZEPEK ${ }^{3}$, KENNETH STRZEPEK ${ }^{4}$ and C. ADAM SCHLOSSER ${ }^{4}$ \\ ${ }^{1}$ Department of Civil, Environmental and Architectural Engineering, University of Colorado, Boulder, CO, USA \\ ${ }^{2}$ School of Planning, Architecture and Civil Engineering, Queen's University, Belfast, UK \\ ${ }^{3}$ Climate and Civil Systems Group, University of Colorado, Boulder, CO, USA \\ ${ }^{4}$ MIT Foint Program on the Science and Policy of Global Change, Boston, MA, USA
}

Received 26 November 2010; accepted 15 December 2010

\begin{abstract}
Government organizations are responsible for strategic decisions regarding the economic development of individual countries and regional areas. This decision-making process is influenced by the certainty of the information presented to government officials. One area where this decision-making influence is challenging government officials is in climate-based events. The past decade has witnessed a significant rise in the number of climate events, as well as the number of people affected by climate events. Far from being under control, evidence and long-term projections suggest that these events are climate-based rather than weatherbased. In these projections, climate change is a global issue with potential impacts for every country. However, the relative impact of these events will be far different in the developed and developing worlds. As detailed in this paper, the authors examined this disparity through an analysis of 10 countries with varying income levels to determine the relative impact of climate change in the context of a single infrastructure element, paved and unpaved roads. Using the latest global climate models combined with economic and infrastructure data, the study highlights the disparity of opportunity costs between high- and low-income countries. Roads are a key element in enabling developing economy communities to have access to basic services, generate an income through agriculture and gain productive employment. The potential for road damage and the inability to invest in new road infrastructure could impact the economic stability of communities. The paper provides a quantitative introduction to these issues and the challenges presented to government organizations when considering the long-term effects of climate change.
\end{abstract}

Keywords: Infrastructure, organization, strategy.

\section{Introduction}

Long-term events often receive less attention than immediate concerns in government organizations since effects may be slow in evolving and fail to have the immediate impact that political entities require. One example of this challenge is the onset of climate change. Recognized events such as earthquakes or hurricanes influence communities to prepare for what is considered an inevitable occurrence of these natural disasters. In contrast, climate change is influencing political discussions, but decisions are generally being delayed as greater certainty in the potential effects is developed. Despite the continued studies on potential long-term effects, many government organizations remain in the study stage rather than moving to any form of action to mitigate the potential effects of climate-based issues. Unfortunately, climate change is not limited to governments that have the economic resources to successfully respond to long-term change. Rather, climate change is a global issue with potential impacts on the developing world that are far more severe than those predicted for the developed world. This paper addresses the challenge that government organizations throughout the world will face in terms of tackling the long-term effects of climate change.

*Author for correspondence. E-mail: chinowsk@colorado.edu

The Engineering Project Organization fournal

ISSN 2157-3727 print/ISSN 2157-3735 online (C) 2011 Taylor \& Francis

http://www.informaworld.com

DOI: $10.1080 / 21573727.2010 .549608$ 
Of particular concern is the impact on the limited infrastructure of developing countries.

Much of the existing climate change literature examines the cost of policies to mitigate climate change (e.g. carbon taxes and cap-and-trade systems), but few studies address the costs of climate change adaptation (Claussen et al., 2001; Stern, 2007; Nordhaus, 2008). While many studies have assessed the impacts associated with responding to extreme weather events and other natural disasters, these analyses do not account for systemic changes in the intensity or the frequency of extreme events or for long-term changes in climatic norms (World Bank, 2009). This creates a challenge for public officials attempting to prepare for climate change by anticipating the potential cost of climate change impact on public infrastructure (TRB, 2008). While significant study has been done on the cost of natural disasters in various contexts, climate change presents a new challenge for public officials. Given that modern civilization has not experienced a significant climate change event, few cost models specific to climate change impacts exist from which to anticipate potential costs. Additionally, the combination of the long-term nature of the event and the conflicting scenarios depicted for climate change creates a significant amount of uncertainty in the planning process. Based on research being conducted by the authors for the World Bank (2009), the United Nations and the State of Alaska (Larsen et al., 2008), this paper sets forth one step towards building a strategy to cope with this uncertainty by quantitatively examining the relative impact of climate change on developed and developing economies. The analysis is placed in the context of a single, project-based infrastructure, paved and unpaved roads, in 10 countries representing both geographic and economic diversity.

Through this analysis, the paper addresses the critical question of, 'Does climate change have a greater relative impact economically on developing countries versus developed countries?' The importance of this question is that monetary expenditures alone fail to address the relative impact of climate change on a country. Rather, the critical question that needs to be addressed is how climate change affects countries in terms of their ability to absorb the predicted costs. For developing countries, this absorption includes the ability of the country to continue on a designed development path rather than being forced to reduce or abandon these plans due to the need to redirect funds to climate change adaptation. This paper addresses this question by establishing a metric by which the relative impact of climate change can be measured on the countries of varying economic capacities.

\section{Climate adaptation and developing countries}

Answering the stated research questions relies on two distinct areas of study related to climate change: adaptation and developing world impact. In terms of the first, the existing literature related to climate change adaptation in the infrastructure sector is primarily qualitative in nature with an emphasis on broad recommendations and warnings. The comparative analysis presented in this paper attempts to diverge from this literature base by building on the knowledge accumulated from society's past experience responding to natural disasters and applying the adaptation approaches from these events to climate change. Although single events such as earthquakes or floods are not directly analogous to climate change, the local, regional and national government responses that have been documented over the last several decades provide foundational models from which to anticipate the impact and adaptation response that may occur in response to climate change.

The importance of natural disaster response to climate change is the concept that evolves based on organizational responses to numerous events over time. Specifically, organizations learn from natural events and adapt to the events over time. In this adaptive learning process, organizations offset the effects of natural events on infrastructure by improving the design of the capital stock to offset future negative effects. This type of adaptation is particularly appropriate to infrastructure with extended useful life scenarios, which constitute much of the transport and energy infrastructure of most nations.

Unfortunately, in the specific context of roads, research in climate change and adaptation has focused predominantly on broad qualitative impacts. These studies primarily focus on qualitative predictions of how climate change may impact the use and lifespan of the existing infrastructure. Research completed by the Transportation Research Board in the USA, the Scottish Executives and Austroads in Australia are notable efforts in this regard (AUSTROADS, 2004; Galbraith et al., 2005; TRB, 2008; Industrial Economics, 2010). Within these reports, the authors outline the potential effects of climate change on a spectrum of transport-based activities including shipping, public transport, winter roads and coastal roads among others. In each case, the reports advocate a proactive stance on potential climate impacts, but differ in approaches and the degree of action that may be required. The reports provide a foundation for advocating action in anticipation of climate change, but fall short of placing a quantitative estimate on the potential costs of these actions. 


\section{The developing world and climate change}

In respect to the second issue underlying the current work, developing world impact, the United Nations Climate Change Conference held in Copenhagen, Denmark, in 2009 focused extensive attention to the issue of climate change impacts on the developing world. Currently, the United Nations Framework Convention on Climate Change (UNFCCC) officially recognizes the potential threat that climate change poses on a global basis. A significant proportion of this threat falls in the developing world and those countries least able to adapt to the threats posed. Significant discussions have taken place since the Rio de Janiero Conference (Earth Summit) in 1992, focusing on the adaptation to and mitigation by countries to climate change (UNFCCC, 2010). For developing countries, the emphasis is on identifying the threats posed, adapting to the predicted changes, incorporating the changes into mid-range and long-term development plans and securing funding for the proposed and necessary adaptations (UNFCCC, 2009, 2010).

In the developing world, planning for climate change is complicated by two factors: (1) the lack of existing infrastructure and (2) the widespread changes that are predicted due to climate change. In terms of the first, in 1997, Africa (excluding South Africa) had 171000 $\mathrm{km}$ of paved roads, about $18 \%$ less than Poland, a country roughly the size of Zimbabwe. But with a focus on the completion of the trans-African highways, the quality of existing roads, relied upon by local communities, has been deteriorating. In 1992, about $17 \%$ of sub-Saharan Africa's primary roads were paved, but by 1998 the figure had fallen to $12 \%$ according to the World Bank. At the beginning of this decade, more than $80 \%$ of unpaved roads were considered to be only in fair condition and $85 \%$ of rural feeder roads in poor condition and could not be used during the wet season. In Ethiopia, $70 \%$ of the population has no access to all-weather roads (Mutume, 2002).

The African Development Bank Group has called for an estimated US $\$ 40$ billion per year to help African nations handle the challenges associated with climate change (Kaberuka, 2009). Additionally, the predicted climate change effects are compounding the existing efforts in sustainable development being undertaken by developing nations, including the achievement of the Millennium Development Goals set for 2015 (UNFCCC, 2005). In extreme cases where water security or changes in agriculture threaten the livelihood of certain populations, or in the case of the island nation of the Maldives which is threatened with the disappearance of its territory due to sea-level rises, climate change has additionally been discussed in the context of human rights. The United Nations Human Rights Council passed a resolution in 2009 focusing on the need to address climate change in terms of effects on human rights stating climate change, 'will be felt most acutely by those segments of the population who are already in a vulnerable situation ...' (United Nations, 2009). In summary, developed and developing countries agree that climate change is a significant threat and that adaptation and mitigation measures need to be addressed at the national and international levels.

\section{Current study}

The United Nations Climate Change Conference brought the issue of adaptation to the forefront as it attempted to quantify the monetary need to support climate change adaptation. The current study both narrows this emphasis and expands on current available data. In terms of the former, the study narrows the focus by emphasizing the impact of climate change on a single sector, road transport. In terms of the latter, the study expands upon current analysis by doing a crosscountry comparison over multiple climate scenarios and over an extended period of time. To accomplish this comparison, the paper brings together the engineering analysis of physical climate impacts, the understanding of the macro-level impact on a country's economy, the social understanding of the impact of roads on individual communities and the political understanding of how significant economic events may challenge governmental organizations. In this manner, the paper reflects the inter-disciplinary research required to fully address the issue of climate change impacts on governmental entities.

Within the overall comparison objective, the study attempts to answer the question of whether climate change has a proportionately higher impact on the infrastructure of developing countries than it does on developed countries. A selection of countries with differing income levels is used to draw a comparison on relative impact. For simplification purposes, this impact focuses on a single infrastructure asset, paved and unpaved roads. As a result, the study provides a quantitative comparison of climate change impacts on a single sector across multiple countries of differing income levels.

\section{Selection of countries}

With 195 countries in the world, the first task in the research effort focused upon selecting the set that reflected the goals of the study. The authors achieved this goal by setting forth three criteria for selecting countries as follows (Figure 1): 


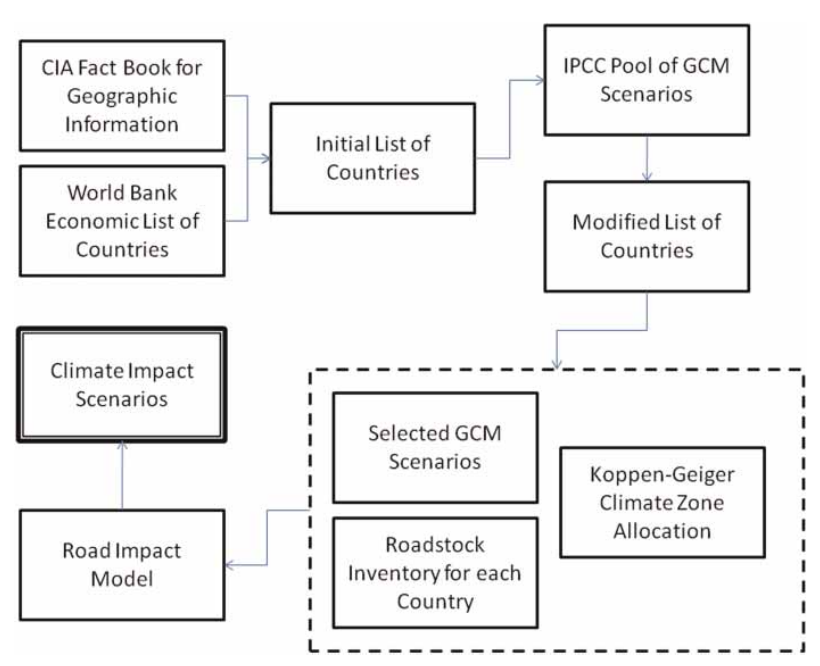

Figure 1 Flowchart of the methodology used to select countries and determine the final results for the climate analysis

(1) the countries should represent both upper- and lower-income categories to provide economic diversity,

(2) the countries should be similar in geographic size to provide consistency in terms of potential infrastructure assets and

(3) the countries needed to reflect geographic representation to examine the impact on a global rather than a regional basis.

From this last requirement, one upper- and one lower-income country would be selected from Asia, Africa, South America and Europe. In addition to these eight countries, a third country was selected in Europe to reflect the differences in northern and southern European climates. Additionally, a third country, New Zealand, was chosen in the Asia region to represent the Oceana region. North America was excluded from the selection process due to the large geographic area of the North American countries.

To assist in the selection process, the authors used the World Bank analytical categorization of countries based on income levels to obtain income levels in each geographic region (World Bank, 2010). Similarly, the authors used the CIA World Factbook to find geographically similar countries in terms of area (CIA, 2010). Finally, initial studies were run on the countries to determine if the countries were projected to experience climate change effects. This last criterion eliminated several countries from consideration. This elimination was not intended to bias the study, but rather was intended to ensure that a comparison of the relative impacts of climate change could be completed.

\section{Overall characteristics of countries}

The overall characteristics of the 10 countries selected for study are illustrated in Table 1. As illustrated, five countries are from lower-income categories and five are from upper-income categories. The countries range from a geographic area of 55974 to $1083301 \mathrm{~km}^{2}$. The population ranges from a low of 4.3 million people to a high of 126.8 million people. The countries range from a low GDP of $\$ 42.8$ billion to a high GDP of $\$ 4141.0$ billion in 2009 dollars. Finally, the countries have a variance in the level of investment in road infrastructure. The countries range from a low of $\$ 127$ million of annual road expenditures or $0.17 \%$ of GDP to a high of $\$ 179.4$ billion in expenditures or $4.33 \%$ of GDP. As illustrated, the majority of the countries have minimal variance in terms of geographic area. However, this is the category that had to be modified to ensure that both economic diversity and climate change impact could be met by the country selections. However, the combination of the three selection criteria provides the underlying similarity that is necessary for the study comparison.

\section{Methodology}

The challenge to establishing a methodology for the current study centred on the variation that exists in the types of data within the current study and the variation in the countries selected for the analysis. Given this variation, it was necessary to divide the study into a number of discrete pieces whose results could then be combined into an overall finding (Figure 1).

\section{Climate zones}

The first requirement for conducting the impact study was to determine the climate zones that exist within each of the selected countries. The climate zone identification is necessary for two reasons: (1) to determine which climate models should be applied to which geographic locations within a country and (2) to determine which infrastructure elements lie within specific climate zones, thus enabling the models to determine impacts from specific climate changes. The climate zone mapping process chosen for the study is the KoppenGeiger classification. Established by Vladimir Koppen between 1884 and 1936, the Koppen method of climate zone classification focused on the annual temperature and precipitation cycles throughout the world (Lohmann et al., 1993). Using these cycles as a basis, Koppen established five primary climate classifications: tropical, arid, temperate, cold and polar. Further dividing these primary categories according to levels of 
Table 1 Characteristics of countries selected for the current study

\begin{tabular}{|c|c|c|c|c|c|c|c|c|}
\hline Country & $\begin{array}{l}\text { World Bank } \\
\text { income level }\end{array}$ & $\begin{array}{c}\text { Population } \\
\text { (2010 Est) } \\
\text { (millions) }\end{array}$ & $\begin{array}{l}\text { Total land } \\
\text { area }\left(\mathrm{km}^{2}\right)\end{array}$ & $\begin{array}{c}\text { GDP } \\
(2009) \\
\text { (\$ billions } \\
\text { USD) }\end{array}$ & $\begin{array}{c}\text { Road } \\
\text { expenditure } \\
(2009) \\
(\$ \text { millions } \\
\text { USD) }\end{array}$ & $\begin{array}{c}\text { Road } \\
\text { expenditure } \\
\% \text { GDP }\end{array}$ & $\begin{array}{l}\text { Total KM } \\
\text { road }\end{array}$ & $\begin{array}{c}\% \\
\text { Paved } \\
\text { roads }\end{array}$ \\
\hline Bolivia & Lower-middle & 9.9 & 1083301 & $\$ 45.1$ & $\$ 160.9$ & $0.36 \%$ & 62479 & $7.00 \%$ \\
\hline Cameroon & Lower-middle & 19.3 & 472710 & $\$ 42.8$ & $\$ 157.5$ & $0.37 \%$ & 51346 & $8.37 \%$ \\
\hline Croatia & Upper-middle & 4.5 & 55974 & $\$ 79.2$ & $\$ 1911.5$ & $2.41 \%$ & 29038 & $89.13 \%$ \\
\hline Ethiopia & Lower & 88.0 & 1000000 & $\$ 76.7$ & $\$ 126.8$ & $0.17 \%$ & 36469 & $19.14 \%$ \\
\hline Italy & High & 58.1 & 294140 & $\$ 1756.0$ & $\$ 130.6$ & $7.44 \%$ & 487700 & $81.01 \%$ \\
\hline Japan & High & 126.8 & 364485 & $\$ 4141.0$ & $\$ 179.4$ & $4.33 \%$ & 1196999 & $79.29 \%$ \\
\hline New Zealand & High & 4.3 & 267710 & $\$ 116.5$ & $\$ 2021.7$ & $1.74 \%$ & 93748 & $65.41 \%$ \\
\hline The Philippines & Lower-middle & 99.9 & 298170 & $\$ 324.8$ & $\$ 757.1$ & $0.23 \%$ & 200037 & $9.90 \%$ \\
\hline Sweden & High & 9.1 & 410335 & $\$ 333.2$ & $\$ 3718.1$ & $1.12 \%$ & 427045 & $31.66 \%$ \\
\hline Venezuela & Upper-middle & 27.2 & 882050 & $\$ 355.2$ & $\$ 1052.1$ & $0.30 \%$ & 96155 & $33.60 \%$ \\
\hline
\end{tabular}

humidity and precipitation, Koppen ultimately presented a map with 31 distinct climate zone classifications. These climate zone classifications were refined and formalized into a global map in 1961 by Rudolf Geiger. Together, this work is the basis of the Koppen-Geiger global classification maps used throughout the world today.

Utilizing GIS maps of the selected countries, overlays were created for each country to determine the percentage of each country that lay within a specific KoppenGeiger climate zone. Depending on the country, this division ranged from two to four climate zones. It should be noted that in countries with greater geographic areas such as China, or countries with diverse geographic landscapes, such as Tanzania, this total can reach 10 or more distinct climate zones.

\section{Division of road inventory}

To allocate the road inventory within each country, the authors adopted a percentage allocation methodology. In this method, the authors obtained the total road inventory for each country either through direct data where they were available or through a commercial database of international road data (IRF, 2009). Based on existing classifications, the roads were divided into three categories: primary, secondary and tertiary. The authors did not attempt to validate the classifications that were established by the individual countries. Further, roads were divided into paved and unpaved categories for each of the three classifications based on the percentage of paved roads provided by the data sources, thus giving each country the opportunity to have six distinct road classifications.
The total inventory of each road type for the country was subsequently divided into the climate zones based on the percentage of the country that the zone encompassed. This method is based on the assumption that geographic area is related to the number of roads in a given country. As discussed below, exceptions to this rule exist; however, this provided a starting point from which to do the regional-level analysis. For example, if a country had two climate zones, Zone A which covered $65 \%$ of the country and Zone B which covered the remaining $35 \%$, and $1000 \mathrm{~km}$ of primary paved roads, then $650 \mathrm{~km}$ of primary paved road would be allocated to climate Zone A and $350 \mathrm{~km}$ would be allocated to Zone B. In the same manner, each of the six types of road was allocated between the climate zones. This resulted in allocations of 12-24 total allocations depending on the number of climate zones within a country.

\section{Comparison of population centres to climate zones}

Although the majority of the selected countries have a comparable population distribution to the climate zones, this is not the case in every circumstance. In certain geographic areas such as North Africa or Northern Europe, population centres can differ significantly from the overall physical definitions of the climate zones. For example, in North Africa, the geographic zone delineation is dominated by arid desert climates. However, the population densities are dominant within the narrow bands of temperate climate found along the coast of the Mediterranean Sea. This impacts the geographic allocation method of road 
inventory division by placing roads in proportions which are different from the physical zone allocations.

The authors determined whether such a population imbalance existed within the selected countries by overlaying existing GIS population distribution maps over the climate zones (ESRI, 2010). Where population distributions differed from the climate zone allocations, the authors modified the road allocations to reflect the general population imbalance within the country. For example, if a climate zone that encompassed only $20 \%$ of the country contained $40 \%$ of the country's population, the road inventory allocation would be adjusted to reflect the $40 \%$ distribution rather than the $20 \%$ physical distribution. This method was adopted based on the assumption that greater population levels require greater levels of infrastructure development and thus a greater density of roads within those areas.

\section{General Circulation Models (GCM)}

Once the allocations of the road inventories were completed, a determination was required as to what climate models should be used for each country. The climate models were selected from the pool approved by the IPCC and represent both a variance in projected precipitation increases as well as a variance in scenarios of how a given country may pursue industrial development (IPCC, 2007). Each of these climate models contains annual predicted precipitation and maximum temperatures. In an effort to get a broad picture of the potential effects of climate change and to avoid focusing on extreme possibilities, three different climate scenarios were chosen: a global effect, a maximum country effect and a median country effect. The global perspective is adopted from earlier work by the authors for the World Bank and represents a global wet, NCAR_ccsm3-A2, and a global dry, CSIRO_mk3-A2, scenario based on soil moisture effects (World Bank, 2009). These two models were run for each country as a baseline global climate model.

In contrast to the global model, the country models were selected based on the impact that the climate model indicated for a specific country. Focusing on the effects of climate on infrastructure, the wet and hot properties of the 22 accepted models were focused upon in this selection process. Specifically, the effects of each model were analysed in terms of precipitation and temperature averages for each decade from 2010 through 2100. For precipitation, the annual precipitation for each decade was used to determine the total precipitation increase through 2100 in the specific country. Based on this total, models were selected based on the maximum annual precipitation predicted and the median precipitation predicted for each country. Similarly, the maximum temperature was used to select the models which predicted the greatest temperature increase and the median temperature increase. The completion of the selection process provided six selected models for each country; a global wet and a global dry, a country maximum wet and a country maximum dry and a country median wet and a country median dry.

\section{Road impacts}

The World Bank (2009) has previously detailed the authors' approach to determining the impacts of climate change on paved and unpaved roads. However, to summarize this process, the methodology focuses upon the effects of precipitation and temperature (stressors) on paved and unpaved road surfaces. Specifically, the impacts are translated into stressorresponse values which are the quantitative impacts that a specific stressor has on a specific infrastructure element based on engineering data, materials analysis and previous impact studies. For example, an increase in the precipitation level is going to have a specific quantitative impact on an unpaved road in terms of decreased lifespan. These stressor-response factors are divided into two general categories: impacts on new construction costs and impacts on maintenance costs. New construction cost factors focus on the additional cost required to adapt the design and construction when rehabilitating an asset to changes in climate expected to occur over the asset's lifespan. Maintenance cost effects are those maintenance costs, either increases or decreases that are anticipated to be incurred due to climate change to achieve the design lifespan. In each of these categories, the underlying concept is to retain the design life span for the structure. This premise was established as a baseline requirement due to the preference for retaining infrastructure rather than replacing the infrastructure on a more frequent basis.

The stressor-response values for new construction costs encompasses two general approaches. The first approach estimates stressor-response values for paved roads based on the cost associated with a change in building code updates, while the second more directly estimates the incremental costs for unpaved roads based on design changes. The building code methodology focuses on the concept that new structures such as paved roads will be subject to material or building method changes if it is anticipated that a significant climate change stressor will occur during their projected lifespan. The readily available data from pavement specialists suggest that such updates would occur with every $10 \mathrm{~cm}$ increase in precipitation or $6^{\circ} \mathrm{C}$ maximum pavement temperature increase (Lea International, 1995; AASHTO, 2000). It should be noted that these thresholds are a key assumption in this study and 
further refinement of these thresholds is a primary focus of continuing work in this area.

For unpaved roads, a direct approach is used for estimating the cost impact of changes in climate stressors. Under this approach, the stressor-response relationship for unpaved roads associates the change in construction costs with a $1 \%$ change in maximum monthly precipitation. Research findings have demonstrated that $80 \%$ of unpaved road degradation during its lifetime can be attributed to precipitation (Ramos-Scharron and MacDonald, 2007). The remaining $20 \%$ is attributed to factors such as the tonnage of traffic and traffic rates. Given this $80 \%$ attribution to precipitation, we assume that the base construction costs for unpaved roads increase by $80 \%$ of the total percentage increase in the maximum monthly precipitation. The readily available data suggest no relationship between temperature and the cost of building unpaved roads.

Both approaches assume perfect foresight with respect to climate change. Therefore, these stressorresponse values represent the relationship between infrastructure construction costs at the time of construction and the changes in climate projected during the infrastructure's lifespan.

Similar to the development of stressor-response values for new construction costs, two basic methodologies were adopted for maintenance costs. The first approach, used for paved roads, is based on the cost of preventing a reduction in lifespan that may result from changes in climate-related stress. To estimate the reduction in lifespan that could result from an incremental change in climate stress, it is assumed that such a reduction is equal to the percent change in climate stress, scaled for the stressor's effect on maintenance costs. Research has shown that ongoing maintenance for paved roads that is precipitation-related accounts for $4 \%$ of maintenance costs and temperature-related maintenance accounts for $36 \%$ of costs (Miradi, 2004). After estimating the potential reduction in lifespan associated with a given climate stressor, the costs of avoiding this reduction in lifespan is calculated by the product of (1) the potential percent reduction in lifespan and (2) the base construction costs of the asset. Therefore, a $10 \%$ potential reduction in lifespan has an estimated increase in maintenance costs of $10 \%$ of base construction costs.

Finally, to estimate the stressor-response values for unpaved road maintenance costs, an approach is adopted following that outlined above for unpaved road new construction costs. More specifically, changes in unpaved road maintenance costs are associated with a $1 \%$ change in the maximum monthly precipitation. As indicated above, research has demonstrated that $80 \%$ of unpaved road degradation can be attributed to precipitation, while the remaining $20 \%$ is due to traffic rates and other factors (Ramos-Scharron and MacDonald 2007). Given this $80 \%$ attribution to precipitation, maintenance costs increase by $0.8 \%$ with every $1 \%$ increase in the maximum of the maximum monthly precipitation values projected for any given year.

Utilizing these approaches for determining cost impacts on rehabilitation and maintenance over the lifetime of a road asset, the annual maintenance and rehabilitation cost impacts were calculated through 2100 based on each of the six model scenarios. As noted in Limitations section at the end of this paper, the authors make assumptions in calculating these costs which affect the overall quantitative outputs. Specifically, the authors adopt existing material impact studies for paved and unpaved roads. Although these studies do not reflect the condition found in every physical location, they provide an initial starting point for the current work. However, it must be noted that estimates will differ if local conditions and materials are analysed in specific location contexts. Additionally, the impacts from the GCM models selected are based on specific decisions to adopt those models. Alternative models and uncertainty in modelling future climate scenarios will affect specific quantitative results.

\section{Determination of opportunity cost}

The final challenge in setting the methodology for the current study was establishing a common evaluation metric that could be used for each of the countries. The difficulty in this determination is the variation in the countries in terms of amount of current road inventory, annual expenditures on roads, the GDP of the country and the projected cost of climate change for each country. Given these variances, a metric was required that reflects the relative impact on the country while not overly weighting the total cost of climate change on the country. The solution to this issue was the establishment of an opportunity cost associated with each country. In quantitative terms, the opportunity cost is defined as,

$$
\mathrm{OC}_{x}=\frac{\mathrm{CC}_{x} / \mathrm{SRC}_{x}}{\mathrm{PR}_{x}},
$$

where $X$ is a specific country, OC the opportunity cost for a country in percentage, CC the total estimated climate change cost for a country including both maintenance and new costs through 2100, SRC the cost of constructing a kilometer of new, secondary paved road and PR the current paved road inventory within a country in kilometres.

The equation indicates that the opportunity cost for a country is equal to the total percentage increase in the 
paved road network that could have been achieved if the money was not being diverted to climate change adaptation. In this manner, opportunity cost is the degree to which a country could enhance its road infrastructure if climate change would not be impacting the road expenditures. Roads, specifically those that are accessible year-round, have a significant impact upon communities. Indicators such as maternal health, level of education, poverty, gender equity, economic development and transport are higher in areas where the rural areas have greater accessibility to developed urban centres and there is greater connectivity between communities (Roberts et al., 2006). Therefore, the measurement is intended to have an underlying economic component that reflects the need to enhance economic development within a country. Although this measurement may be of greater importance to developing countries, it is intended to indicate the relative impact of climate change on a country's road infrastructure so this limitation is acceptable since a greater impact is seen on countries with a lower installed road base.

\section{Study results}

Arriving at an answer to the current research question requires the question to be answered in a consistent context over each country based on the available options including maximum effects based on countryspecific climate models, the global models or the median effect models. The current study established this consistency by establishing four climate effect categories based on the six climate models chosen for each country. This provides specific, comparative approaches based on the available climate models:

(1) global effect: the average effect of the global wet and the global dry climate models on the infrastructure

(2) country maximum: the average effect of the models that had the greatest effect on the specific country in terms of temperature and precipitation

(3) country median: the average effect of the models that displayed the median effect on the specific country in terms of temperature and precipitation

(4) maximum effect: the maximum effect from the previous three categories annually in terms of overall cost impact on the infrastructure.

From these four effect categories, the results of the analysis are illustrated in Table 2 . The table is organized based on the overall opportunity cost percentage derived from the maximum effect models. However, the data from the maximum effect, global effect and country median are presented to illustrate the three perspectives from which the final analysis was conducted. Country maximum is omitted since maximum effect includes any maximums that may be encountered in the country specific data. Table 2 includes the following four derived components.

(1) Opportunity cost \%: As described previously, this is the percent of the paved road network that could have been increased if the expenditures were not diverted to adapting to climate change.

(2) Climate change expenditures without adaptation: This is the total expenditure on climate change that would be required through 2100 to maintain the current road inventory. This includes just increased maintenance costs that originate from climate change factors. It assumes no design standards have been put in place to account for increased precipitation or temperature. Finally, only the existing road inventory total is accounted for, and not increases due to an increase in the total kilometres of road inventory.

(3) Climate change expenditures with adaptation: This is the total expenditure on climate change required through 2100 to maintain the current road inventory with the inclusion of adaptation strategies. Specifically, this total includes the code adaptation approach for paved roads introduced previously to ensure that when a road is rehabilitated or repaved it is built to a standard that anticipates climate change effects. For unpaved roads, it assumes standard maintenance.

(4) Maximum expenditure decade: This is the decade where it is anticipated that the greatest expenditures will be required to offset climate change effects.

To further illustrate how these results summarize the individual country results, Table 3 shows the four data components for Ethiopia by decade based on the maximum effect models. As illustrated, the data indicate that an initial cost is incurred as maintenance costs rise for existing paved roads which are not designed for climate change effects. However, the costs decline as adaptation occurs and the effect of climate change is moderate through 2050. At this point, climate change effects increase and a greater percentage of the expenditures is required to offset the potential damage to the roads. It can also be seen at this point how adaptation significantly decreases the cost of climate change as paved roads are constructed 
Table 2 Derived values for each country in the three comparison scenarios

\begin{tabular}{|c|c|c|c|c|c|c|c|c|c|c|c|c|}
\hline \multirow[b]{2}{*}{ Country } & \multicolumn{3}{|c|}{ Opportunity cost percentage } & \multicolumn{3}{|c|}{$\begin{array}{c}\text { Total cost of climate change with } \\
\text { adaptation (\$ million, } 2009 \\
\text { USD) }\end{array}$} & \multicolumn{3}{|c|}{$\begin{array}{l}\text { Total cost of climate change } \\
\text { without adaptation (\$ million, } \\
2009 \text { USD) }\end{array}$} & \multicolumn{3}{|c|}{ Greatest expenditure decade } \\
\hline & Max & Global & Median & Max & Global & Median & Max & Global & Median & $\operatorname{Max}$ & Global & Median \\
\hline Bolivia & $211 \%$ & $31 \%$ & $119 \%$ & 138.2 & 20.3 & 78.0 & 309.1 & 152.3 & 155.2 & 2060 & 2100 & 2050 \\
\hline Ethiopia & $138 \%$ & $67 \%$ & $33 \%$ & 144.8 & 70.3 & 34.7 & 316.4 & 203.6 & 42.8 & 2090 & 2090 & 2020 \\
\hline Cameroon & $92 \%$ & $37 \%$ & $9 \%$ & 59.6 & 23.6 & 5.7 & 263.7 & 96.7 & 113.2 & 2100 & 2100 & 2020 \\
\hline Croatia & $84 \%$ & $3 \%$ & $16 \%$ & 326.3 & 11.1 & 62.6 & 3504.2 & 1452.4 & 2179.4 & 2020 & 2100 & 2030 \\
\hline The Philippines & $35 \%$ & $19 \%$ & $15 \%$ & 102.6 & 55.8 & 45.2 & 581.9 & 261.5 & 290.4 & 2100 & 2100 & 2100 \\
\hline Venezuela & $19 \%$ & $9 \%$ & $2 \%$ & 194.7 & 44.2 & 7.4 & 1343.3 & 85.4 & 154.9 & 2020 & 2020 & 2100 \\
\hline Sweden & $12 \%$ & $9 \%$ & $3 \%$ & 243.6 & 182.5 & 69.6 & 3449.6 & 2839.0 & 1359.7 & 2090 & 2100 & 2090 \\
\hline New Zealand & $9 \%$ & $3 \%$ & $3 \%$ & 83.9 & 25.1 & 31.9 & 2057.5 & 529.5 & 924.3 & 2100 & 2100 & 2100 \\
\hline Japan & $7 \%$ & $2 \%$ & $4 \%$ & 1052.0 & 321.3 & 621.3 & 5101.1 & 2027.3 & 2222.4 & 2100 & 2090 & 2090 \\
\hline Italy & $4 \%$ & $1 \%$ & $2 \%$ & 224.7 & 54.3 & 137.0 & 8253.1 & 5107.9 & 5643.5 & 2030 & 2070 & 2030 \\
\hline
\end{tabular}


Table 3 Example of impact costs derived for Ethiopia by decade through 2100

\begin{tabular}{|c|c|c|c|}
\hline Decade & $\begin{array}{l}\text { Opportunity } \\
\text { cost } \\
\text { percentage }\end{array}$ & $\begin{array}{c}\text { Total cost of } \\
\text { climate change } \\
\text { with adaptation } \\
\text { (\$ million, } 2009 \\
\text { USD) }\end{array}$ & $\begin{array}{l}\text { Total cost of } \\
\text { climate change } \\
\text { without } \\
\text { adaptation (\$ } \\
\text { million, } 2009 \\
\text { USD) }\end{array}$ \\
\hline 2020 & 4.85 & 3.2 & 3.0 \\
\hline 2030 & 4.88 & 3.2 & 3.1 \\
\hline 2040 & 17.45 & 11.5 & 12.0 \\
\hline 2050 & 75.46 & 49.5 & 50.2 \\
\hline 2060 & 24.73 & 16.2 & 41.1 \\
\hline 2070 & 38.76 & 25.4 & 57.0 \\
\hline 2080 & 18.33 & 12.0 & 47.5 \\
\hline 2090 & 15.18 & 10.0 & 41.2 \\
\hline 2100 & 11.00 & 7.2 & 53.6 \\
\hline
\end{tabular}

with enhanced drainage, permeable bases and asphalt mix designs among other adaptations that accommodate the precipitation and temperature increases. In this adaptation approach, the roads are designed to offset the potential damages caused by climate stressors and therefore decrease the potential cost of climate change effects. The cost for these changes is reflected in the 'With adaptation' column together with the maintenance costs for both paved and unpaved roads. The 'Without adaptation' column indicates the cost required to maintain the current road inventory without these design adaptations.

As illustrated in this table, climate change costs are dependent on the climate change pattern in a specific country. Depending on when a temperature or precipitation increase is predicted and when the intensity of this change occurs will significantly alter the cost profile for the specific country. For example, the Philippines experience a relatively small variance in terms of climate change costs and opportunity percentage in the modelling results when compared with Bolivia and Ethiopia. This variance is further reflected by the expenditure decade for these countries. The Philippines are consistent with each model that the greatest expenditure decade is in 2100 . However, Bolivia indicates a different maximum expenditure decade depending on the model selected. These variances are a direct result of the climate patterns that are predicted from the underlying models. Depending on the variance in the climate change and the intensity of the change, the expenditure and opportunity cost results will either differ significantly or remain relatively consistent. For this reason, the study looked at six different models for each country to arrive at results that could be compared.

\section{The max effect comparison}

The first level of comparison between the impacts is accomplished through a descriptive analysis. At this level, the maximum effects data is selected as it has been the most often requested data from the authors by funding agencies and government officials as they anticipate the effects of climate change. From this perspective, the opportunity costs illustrate the greatest variance in the results. The largest effect level is incurred by Bolivia with an opportunity cost of $211 \%$. This translates to meaning that Bolivia could have increased its current paved road inventory of $4375 \mathrm{~km}$ to over $13600 \mathrm{~km}$ by 2100 with the funds that were diverted to climate change adaptation. Similar to Bolivia, both Ethiopia and Cameroon in the African sector, as well as Croatia in the European sector and the Philippines in the Asian sector, all experience an opportunity cost of greater than $25 \%$. Within this group, the African countries experience the greatest impact after Bolivia with Ethiopia experiencing a $138 \%$ opportunity cost and Cameroon experiencing a $92 \%$ opportunity cost impact. The reasoning for this follows the same path for Bolivia, Ethiopia, Cameroon and the Philippines. In each case, the countries have a low percentage of paved roads in the overall road inventory. Therefore, since unpaved roads sustain heavy damage from precipitation, the amount of resources required to maintain the unpaved roads on a wide-scale basis is significant and removes the opportunity to increase the small inventory of paved roads. For Croatia, the percentage of paved roads is high at $89 \%$, but the total number of paved roads is low. Thus, the expense attributed to climate change eliminates the potential to increase the small inventory as the resources are redirected to the existing paved inventory. Thus, the factor of a small inventory of paved roads leads directly to a large opportunity cost when resources need to be redirected away from expanding this inventory.

From an expenditure perspective, Bolivia will see the greatest impact during the decade of 2050 where $31 \%$ of annual expenditures will be diverted to climate change, assuming adaptation is put in place to reduce the total climate change effect. This expenditure is the sum of the costs for adaptation and the maintenance of unpaved roads where it is difficult to mitigate damage unless the roads are transformed to all-weather roadways. The expenditure factor sees the greatest variance between the countries with six of the countries incurring the greatest expenditures in the second half of the century and four incurring the greatest impact in the first half of the century. This difference highlights the dependence on the climate change pattern that an individual country will experience. Variances in precipitation increases or temperature increases will have 
varying effects on roads depending on existing road inventory, the intensity of the change and the current design standard. These differences are independent of the income level of the country, but may significantly impact the necessity of the response in terms of time to react to the expected results. Finally, Table 2 highlights the difference between adapting to climate change and foregoing adaptation. For example, if Bolivia foregoes adaptation, then it will incur approximately $\$ 310$ million of impact versus $\$ 138$ million of impact if adaptation policies are put in place. As seen in Table 2, the differences experienced by each country are significant when extrapolated over a century of expenditures. Eight of the 10 countries have a savings of over $75 \%$, while the remaining two experience a savings of over $50 \%$. Although some may argue that the utility cost of adapting should be reduced due to the fact that the realization of the savings may not occur for over a decade, the result of not adapting is of such a substantive amount that short-term thinking should be discouraged whenever possible.

\section{The relative impact}

The results in Table 2 provide the objective data from which to address the underlying research question of whether climate change has a greater relative impact on developing countries than developed countries. Answering this question focuses on the opportunity costs data. As illustrated, four of the five countries with the largest opportunity cost, and the top three, are from the lower-income countries. From every metric, GDP, existing road network, percentage of paved roads and road expenditures, these lower-income countries trail the remaining countries in the study. The only exception to this is Croatia at number four which, although it is categorized as an upper-middle-income country, is still on the lower end of the income spectrum in terms of its European neighbours. Additionally, the difference in the opportunity cost between the countries at the top of the list and those at the bottom is significant (Figure 2). While the lowest three countries have an opportunity cost of under $10 \%$ each, the top three countries are experiencing impacts of 10 times greater than this at a minimum.

The second area where relative impact can be analysed is in terms of expenditure percentages. As illustrated, the four lowest-impact countries never exceed $1 \%$ of expenditures in any decade. Thus, although these countries may experience a large gross impact in terms of costs, the net effect is minimal on overall expenditures. In contrast, the top two countries regularly experience double-digit expenditures during each decade and the third country, Cameroon, never experiences less than a $2 \%$ expenditure impact. This expenditure requirement translates to a greater shift in resources for the lower-income countries away from investment in a new infrastructure.

The counter-argument to the relative impact discussion is the advocacy of the gross impact perspective. In this perspective, the total amount spent on climate change should be used as the determinant of impact. From this perspective, four of the top five countries in terms of total climate change expenditures are all upper or high income countries. At the top of this list is Japan with an expenditure of over $\$ 1$ billion with adaptation and Italy with an expenditure of over $\$ 8$ billion with no adaptation. Although this measure was considered as a basis for the study, it was rejected due

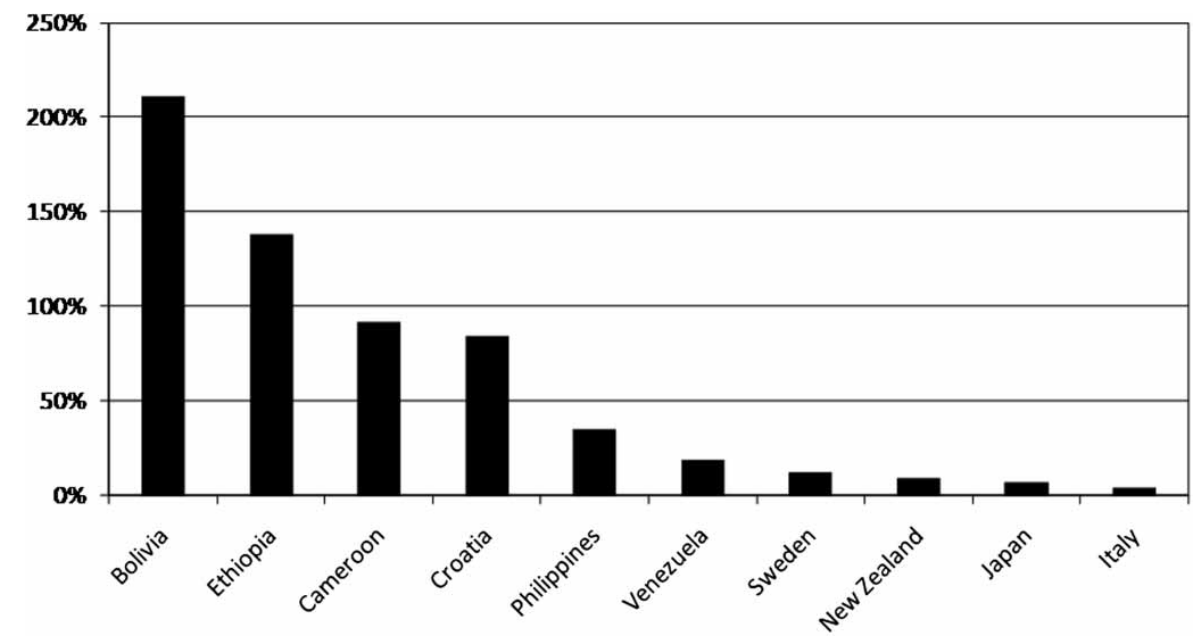

Figure 2 The cumulative opportunity costs as percentage opportunity lost to expand the existing paved road network through 2100 illustrate the relative impact of climate change on lower-income countries versus higher-income countries 
to the fact that it does not reflect relative impact. Specifically, the lower-income countries suffer from a dual issue. First, these countries cannot afford to expend as much resources as is required on their road infrastructure. For example, Bolivia expends just $0.36 \%$ of GDP or $\$ 163$ million on roads while Japan expends $4.33 \%$ of GDP or $\$ 179$ billion on its road infrastructure. To compensate, many lower-income countries depend on unpaved or gravel roads as the basis for the country infrastructure. As illustrated in Table 1, the relative percentage of paved to unpaved roads is much higher in the lower-income countries. This lack of spending leads to the second related issue, the dependence on the roads in place. Since the road network in lower-income countries lacks the density $(0.06 \mathrm{~km} /$ $\mathrm{km}^{2}$ in Bolivia) of that found in higher-income countries (3.16 km/ $\mathrm{km}^{2}$ in Japan), communities are overly dependent on the minimum number of roads in place. Thus, the value of each road in terms of dependence is higher where the road network lacks sufficient density. The bottom line from this is that higher-income countries put in place a greater number of roads and thus experience a greater gross dollar amount impact from climate change. However, this factor does not reflect the impact of the damage on the country due to the value of a single road to the local population.

In summary, the total expenditure on climate change was found to not reflect the relative impact of climate change on the selected countries. Rather, the opportunity to further develop road infrastructure is the measure which reflects the importance of the expenditure shift to the selected countries. From this perspective, the quantitative results illustrate the order of magnitude greater impact on the lower income, developing countries than that found for developed countries.

\section{Limitations}

The current study is based on several key components which introduce uncertainty into the quantitative analysis within the study. The climate data presented here are based on the World Climate Research Programme's (WCRP's) Coupled Model Intercomparison Project phase 3 (CMIP3) multi-model dataset (Meehl et al., 2007). The data set represents current approaches to modelling potential climate change, but is still based on probabilistic modelling. Thus, a degree of uncertainty is introduced in terms of climate impacts. This is one reason why the current study utilizes multiple climate models to arrive at conclusions. Additionally, as stated previously, the study relies on existing material studies to derive the impact stressors. Although the study bases its findings on recognized authorities and studies, the quantitative cost estimates are dependent on the findings from these and similar studies. Issues such as specific pavement types, local conditions, construction and maintenance techniques can all combine to impact specific cost impacts. Therefore, the quantitative cost results may differ based on alternative studies.

These limitations should be considered when analysing the quantitative results of this study. However, the qualitative relationships presented here will remain consistent even if the referenced studies are altered. Specifically, the relative impact on the countries in the study will remain consistent and the overall findings remain as stated.

\section{Discussion and conclusion}

How climate change may affect organization decisionmaking at the government and community levels if road infrastructure is damaged over a sustained period of time will be context-specific, reflecting factors such as geographic location; economic, social and cultural characteristics and the prioritization and concerns of the government entities. However, the potential degradation of roads presents a significant economic threat, particularly in developing countries. Roads are a lifeline to alleviating poverty since investment in access to rural areas and transport improves the living conditions of the poor (Khandker and Koolwal, 2010). Consequently, roads, which have a powerful effect on mobility and choice, continue to merit priority by national governments (Simon, 1996).

The importance of roads to development and longterm growth requires public officials to balance shortterm needs versus long-term planning. The addition of potential climate change effects increases the requirement for balance as the potential benefit from a decision may not appear for several decades. In the context of developing countries, the question becomes more complex as resource limitations make the consequences of long-term decision-making potentially life-threatening. However, is this challenge brought to an additional level of complexity due to unequal consequences of climate change on developing countries? This paper addresses this question by asking whether climate change has a greater relative impact on developing countries than developed countries when put in the context of infrastructure impact. The study utilized a methodology that combined climate science with engineering material studies to address the question. The answer based on the current study of 10 countries that are both geographically and economically diverse is confirmed based on the collected data. 
The study illustrates that based on the impact of predicted temperature and precipitation changes, the opportunity cost to developing countries is significantly greater than that for developed countries. Although the gross dollar impact is greater on developed countries due to the greater inventory of roads, the relative impact on these countries is minimal due to the relative proportion of climate change impact to annual expenditures. In contrast, developing countries will be forced to transfer a significant amount of annual expenditures to offset the effects of climate change on road infrastructure. This loss of opportunity is the basis for the conclusion that climate change does have a greater impact on developing countries than developed countries. The challenge to governmental organizations is how to incorporate a multitude of conflicting requirements into a cohesive policy that achieves balance between short-term needs and the potential long-term effects of climate change on infrastructure.

\section{Acknowledgements}

This research is partly funded by a grant from the University of Copenhagen. The authors also recognize the World Bank for supporting the initial work that enabled the final comparison study. The authors acknowledge the modelling groups, the Program for Climate Model Diagnosis and Intercomparison (PCMDI) and the WCRP's Working Group on Coupled Modelling (WGCM) for their roles in making available the WCRP CMIP3 multi-model data set. Support of this data set is provided by the Office of Science, US Department of Energy. Finally, the authors acknowledge Xiang Guo, David Johnson and William Farmer JP for data analysis.

\section{References}

AASHTO (2000) AASHTO Provisional Standards, American Association of State Highway and Transportation Officials, Washington, DC.

AUSTROADS (2004) Impact of Climate Change on Road Infrastructure, Austroads Publication No. AP-R243/04, Sydney, Australia.

CIA (2010) The World Factbook, Central Intelligence Agency, available at https://www.cia.gov/library/publications/theworld-factbook/

Claussen E., Cochran V.A. and Davis D. (2001) Climate Change: Science, Strategies \& Solutions, Brill Academic Publishers, Leiden, The Netherlands.

ESRI (2010) ArcGIS Version 10, ESRI, Redlands, CA.

Galbraith R.M., Price D.J. and Shackman L. (2005) Scottish Road Network Climate Change Study, Scottish Executive, Edinburgh, Scotland.
Industrial Economics (2010) Costing Climate Impacts and Adaptation: A Canadian Study on Public Infrastructure, prepared for National Round Table on the Environment and the Economy, Industrial Economics, Inc.

IPCC (2007) Contribution of Working Groups I, II and III to the Fourth Assessment Report \& the Intergovernmental Panel on Climate Change, Core Writing Team, Pachauri R.K. and Rosinger, A. (eds.), IPCC, Geneva Switzerland.

IRF (2009) World Road Statistics 2009, International Road Federation, Geneva, Switzerland.

Kaberuka D. (2009) Kaberuka: Africa Needs USD 40 Billion/ Year in Climate Aid, African Development Bank Group, available at http://www.afdb.org/en/news-events/article/ climate-change-conference-an-opportunity-for-africa-6671/ (accessed 12 February 2009).

Khandker S.R. and Koolwal G.B. (2010) How infrastructure and financial institutions affect rural income and poverty: evidence from Bangladesh. The fournal of Development Studies, 46(6), 1109-137.

Larsen P.H., Goldsmith S., Smith O., Wilson M., Strzepek K., Chinowsky P. and Saylor B. (2008) Estimating the future costs of Alaska public infrastructure at risk from climate change. Global Environmental Change, 18(3), $442-57$.

Lea International N.D. (1995) Modeling Road Deterioration and Maintenance Effects in HDM-4, RETA 5549-REG Highway Development and Management Research, prepared for Asian Development Bank.

Lohmann U., Sausen R., Bengtsson L., Cubasch U., Perlwitz J. and Roeckner E. (1993) The Koppen climate classification as a diagnostic tool for general circulation models. Climate Research, 3, 177-93.

Meehl G.A., Covey C., Delworth T., Latif M., McAvaney B., Mitchell J.F.B., Stouffer R.J. and Taylor K.E. (2007) The WCRP CMIP3 multi-model dataset: a new era in climate change research. Bulletin of the American Meteorological Society, 88, 1383-94.

Miradi M. (2004) Artificial neural network (ANN) models for prediction and analysis of ravelling severity and material composition properties, in Mohammadian M. (ed.) CIMCA 2004, Gold Coast, Australia, pp. 892-903.

Mutume G. (2002) Building an efficient road network: public-private partnerships hold the key to regional infrastructure. Africa Recovery, 16(2-3), 23.

Nordhaus W.D. (2008) A Question of Balance: Weighing the Options on Global Warming Policies, Yale University Press, New Haven, CT.

Ramos-Scharron C.E. and MacDonald L.H. (2007) Runoff and suspended sediment yields from an unpaved road segment, St. John, U.S. Virgin Islands. Hydrological Processes, 21(1), 35-50.

Roberts P., Shyam K.C. and Rastogi C. (2006) Rural Access Index: A Key Development Indicator, Transport Sector Board, The World Bank.

Simon O. (1996) The economic impact of transport infrastructure provision: a review of the evidence. Proceedings of the Institution of Civil Engineers - Transport, 117(4), 241-7.

Stern N.H. (2007) The Economics of Climate Change: The Stern Review, Cambridge University Press, Cambridge, MA. 
TRB (2008) Potential Impacts of Climate Change on U.S. Transportation, TRB Special Report 290, Transportation Research Board, Washington, DC.

UNFCCC (2005) Sixth Compilation and Synthesis of Initial National Communications from Parties not Included in Annex 1 to the Convention, Advance Version, UNFCCC, 25 October 2005.

UNFCCC (2009) Support Needed to Fully Implement National Adaptation Programmes of Action (NAPA's), Least Developed Countries, LDC Expert Group 2009, UNFCCC.
UNFCCC (2010) United Nations Framework on Climate Change, available at http://unfccc.int/2860.php

United Nations (2009) Climate Change and Human Rights, United Nations Council on Human Rights, New York.

World Bank (2009) The Costs to Developing Countries of Adapting to Climate Change New Methods and Estimates, Consultation Draft, World Bank.

World Bank (2010) How We Classify Countries, World Bank, Washington, DC. Available at http://data.worldbank.org/ about/country-classifications 